\title{
ORIGINAL ARTICLE \\ Resveratrol derivative production by high-pressure treatment: proliferative inhibitory effects on cervical cancer cells
}

\author{
Yuki Sugahara', Toshiro Ohta'*,,Yoshiki Taguchi', Wataru Kadowaki', Sari Honda', Yasuhiro \\ Kashima², Taiji Matsukawa² and Shigenori Kumazawal** \\ 'Graduate School of Integrated Pharmaceutical and Nutrition Sciences, University of Shizuoka, Shizuoka, Japan; 2UHA \\ Mikakuto Co., Ltd., Osaka, Japan
}

\section{Popular scientific summary}

- Yields of RK4, a conjugate of resveratrol and caffeic acid, were significantly increased under high-pressure conditions.

- RK4 was more effective against cancer cells than resveratrol.

- The present study also suggested that high-pressure treatment is an effective method to produce novel functional food ingredients.

Abstract

Background: In recent years, functional food components have attracted considerable attention. Resveratrol, a food polyphenol, has been widely studied due to its various physiological activities. Previously, we identified a novel resveratrol derivative, named RK4, in food, which is formed by a chemical reaction involving resveratrol and caffeic acid. Furthermore, it was suggested that high-pressure treatment is an important factor in RK4 production.

Objectives: The purpose of this study was to clarify relationships between high-pressure processing and component production and to compare RK4 with the known functional ingredient resveratrol to examine the physiological value of RK4. Through this research, we aimed to develop high-pressure treatment technology that adds new usefulness for food.

Methods: Resveratrol and caffeic acid were reacted under high-pressure treatment and in various conditions of concentration and temperature. RK4 levels in the reaction solution were quantitatively analyzed using liquid chromatography-mass spectrometry. In addition, HeLa cervical cancer cells were exposed to RK4 and resveratrol, and survival rates were measured using the methyl thiazolyl tetrazolium (MTT) method after culturing for $24 \mathrm{~h}$. Activation of an apoptosis-inducing marker was detected by western blotting of cells cultured for $48 \mathrm{~h}$ after addition of the test compounds.

Results: By reacting resveratrol and caffeic acid under high-pressure conditions ( $100 \mathrm{MPa})$, the amount of RK4 produced was significantly increased. It was also found that the reaction temperature and time contributed to this reaction. RK4 exhibited stronger cytotoxicity to HeLa cells than resveratrol. It was also shown that RK4 activated p38, cleaved poly ADP ribose polymerase, and induced apoptosis.

Conclusions: RK4 is a valuable component for further research as a novel compound with wider functionality than that of resveratrol. High-pressure treatment may substantially contribute to the production of novel food ingredients. Further elucidation of the relationships between high-pressure treatment and production of new ingredients has promising potential to guide development of new applications in food processing.

Keywords: food processing; caffeic acid; apoptosis; HeLa; PARP; 338

To access the supplementary material, please visit the article landing page

Received: I8 February 2021; Revised: I3 November 2021; Accepted: 15 November 202 I; Published: 27 January 2022 
$\mathrm{P}$ revention of lifestyle-related diseases, such as arteriosclerosis and diabetes, is known to be highly linked to eating habits. Therefore, interest in health promotion based on specific foods or bioactive food components is rapidly increasing, and research in this area is at present actively undertaken. Among such areas, intake of fruits, vegetables, and grains has been proven to offer protective effects against lifestyle-related diseases (1-4). Such protective role is mainly attributed to the phytochemical contents of certain foods, which are classified as bioactive non-nutrient compounds in fruits, vegetables, grains, and other plants (5). Approximately 10,000 plant-derived chemical substances have been identified to date, and among them, polyphenols are one of the most interesting components because they possess various physiological effects on humans such as lowering blood pressure and reducing inflammation (6).

Resveratrol (3,5,4'-trihydroxy-trans-stilbene) is a wellknown polyphenol found in nuts, grape skins, and wine. Resveratrol is also one of the most widely studied polyphenols, with $>10,000$ reports of it in the literature. This stilbene polyphenol has attracted interest in popular culture over many years because of its potential biological and health benefits. Since a number of epidemiological studies have revealed the cardioprotective benefits of wine $(7,8)$, a field investigating the role of resveratrol has flourished, and a wealth of scientific research has followed (9). Resveratrol has since been identified as a compound that exerts cancer chemoprotective (10) and anti-inflammatory effects (11), improves vascular function (12), extends lifespan, ameliorates aging-related phenotypes $(13,14)$, opposes the effects of a high-calorie diet (15), mimics the effects of calorie restriction (16), and improves cellular function and metabolic health in general (17).

We previously found that resveratrol is partly polymerized with organic acids in foods during their processing to produce new derivatives (18). Among these resveratrol derivatives, we have focused on the component RK4, in which resveratrol and caffeic acid (3,4-dihydroxy cinnamic acid) are polymerized (Fig. 1) because it has been reported to have certain bioactivities stronger than those associated with resveratrol (19). Nuclear magnetic resonance (NMR) assignment of RK4 was summarized in Fig. S1 and Table S1. We have been studying the relationship between RK4 production and food processing, particularly high-pressure processing. High-pressure processing is expected to be a futuristic method of food processing because it does not involve the loss of food flavors and often generates novel proteins and starches with new physical properties that are different from those generated by heat processing (20). In this research, we aimed to determine important relationships involving high-pressure treatment and RK4 production and those mechanisms involved in RK4 production. Regarding the physiological function of RK4, only the growth inhibitory effect on colorectal cancer cells has been reported (18), while other functions are unknown.

During the past few decades, it has been shown that resveratrol could be a good candidate as a therapeutic drug for several disorders such as heart disease, diabetes, obesity, neurological disorders, and cancer $(21,22)$. Jang et al. reported the antitumor effects of resveratrol using a mouse skin cancer model (23), and many studies have shown that resveratrol inhibits cell proliferation and induces apoptosis in cancer cell lines $(24,25)$. Human cervical cancer is the most common form of cancer in women and accounts for a small percentage of all cancer cases diagnosed worldwide. Resveratrol has also been demonstrated to have antiproliferative effects and induces apoptosis in HeLa cells, a cervical cancer cell line (26). Based on these reports, we hypothesized that RK4 may also be expected to have similar bioactivities, and we, hence, decided to measure the antiproliferative effects of RK4 on HeLa cells.

It has been shown that p38 is one of the targets for the induction of apoptosis in cancer cells by various anticancer substances (27) and is a mitogen-activated protein kinase (MAP kinase) that responds to stress stimuli such as cytokines and ultraviolet irradiation. Poly ADP ribose polymerase (PARP) is also one of the targets used to induce apoptosis by resveratrol (28) and is a zinc-dependent eukaryotic DNA-binding protein. It is known that 113 $\mathrm{kDa}$ PARP is cleaved into fragments of $89 \mathrm{kDa}$ and 24<smiles>CC1c2cc(O)c(O)cc2Oc2cc(/C=C/c3ccc(O)cc3)cc(O)c2C1C</smiles>

Fig. 1. Formation of RK4 from caffeic acid and resveratrol reaction. 
$\mathrm{kDa}$, which are considered to be specific markers of the early stages of apoptosis (29). In this study, these two proteins were mainly used to detect the induction of apoptosis by RK4 in HeLa cells.

The purpose of this study was to determine the relationships between high pressure treatment and RK4 production by reacting resveratrol and caffeic acid and to evaluate the potential usefulness of RK4 in cancer prevention by comparing its effects on cervical cancer cells with those of resveratrol. Moreover, through this research, we sought to establish RK4 as a functional food component with beneficial effects.

\section{Materials and methods}

\section{Reagents and NMR analysis}

Resveratrol was obtained from Funakoshi Co., Ltd. (Tokyo, Japan). Caffeic acid-adducted resveratrol (RK4) was synthesized by UHA Mikakuto Co., Ltd. (Osaka, Japan) (18). Dimethyl sulfoxide (DMSO) (Kanto Chemical Co., Inc., Tokyo, Japan) was used to dissolve these reagents. All other chemicals were purchased from SigmaAldrich (St. Louis, MO, USA) unless otherwise stated. NMR spectra were measured on a Bruker AVANCE III 400 instrument (Bruker BioSpin, Billerica, MA, USA). Chemical shifts $(\delta)$ are reported in ppm, and coupling constants $(J)$ are reported in hertz. The chemical shifts in the ${ }^{1} \mathrm{H}$ and ${ }^{13} \mathrm{C}$ NMR spectra were corrected using the residual solvent signals.

\section{Preparation of high-pressure processed samples}

Preparation of high-pressure treated samples was performed by UHA Mikakuto Co., Ltd. Resveratrol and caffeic acid at various concentrations were dissolved in $10 \%$ EtOH (50 mM boric acid) to prepare reaction solutions. These reaction solutions were treated using a high-pressure enzyme reactor TOTAL EXTRACTION (Toyo Koatsu Co., Ltd., Hiroshima, Japan) under different temperatures $\left(50\right.$ and $\left.90^{\circ} \mathrm{C}\right)$, time periods $(1,3,5,6$, and $18 \mathrm{~h})$, and pressure settings $(25,75$, and $100 \mathrm{MPa})$.

\section{Quantitative analysis using LC-MSIMS}

High-pressure processed samples were diluted in $\mathrm{MeOH}$ and filtered through a $0.22 \mu \mathrm{m}$ pore size syringe filter (Hawach Scientific, Shaanxi, China) for HPLC analysis. Chromatographic separation was performed using an HPLC instrument with an ACQUITY UPLC ${ }^{\circledR}$ BEH C18 column $(1.7 \mu \mathrm{m}, \varphi 2.1 \times 100 \mathrm{~mm})$ (Waters Corporation, MA, USA). The eluent was solvent $\mathrm{A}, \mathrm{H}_{2} \mathrm{O}(0.1 \%$ formic acid), and solvent $\mathrm{B}, \mathrm{MeCN}(0.1 \%$ formic acid) (Thermo Fisher Scientific K.K., Tokyo, Japan). A gradient flow program was performed with solvent B: $2 \%(0 \mathrm{~min}), 2 \%$ (1 $\mathrm{min}$ ), $39 \%$ (4 $\mathrm{min}$ ), $41 \%$ (8 $\mathrm{min}$ ), and $98 \%$ (9 $\mathrm{min}$ ) at a flow rate of $0.4 \mathrm{~mL} / \mathrm{min}$. The injection volume was $20 \mu \mathrm{L}$, and three injections were performed for each sample. Mass spectrometry was performed on a TSQ Quantum ${ }^{\mathrm{TM}}$ Access MAX (Thermo Fisher Scientific K.K.) triple quadrupole mass spectrometer in selected reaction monitoring (SRM) scan mode (negative mode). The analytical conditions for RK4 were determined by the infusion method and were performed with collision energy $-29 \mathrm{~V}$, parent ion $\mathrm{m} / \mathrm{z} 361.14$, product ion $\mathrm{m} / \mathrm{z} 345.12$, and tube lens voltage $-142.66 \mathrm{~V}$. In addition, based on the quantitative results, we sought to analyze relationships involving the amount of RK4 produced and the reaction time physicochemically using the following formula:

$$
C_{S}=C_{A} 1+\frac{k_{2}}{k_{1}-k_{2}} e^{-k_{1} t}+\frac{k_{1}}{k_{2}-k_{1}} e^{-k_{2} t}
$$

\section{Cell line and cell culture}

The human HeLa cervical cancer cell line was purchased from CH3 BIOSYSTEMS LLC (Amherst, NY, USA). Cells were cultured in RPMI-1640 medium (Nacalai Tesque, Inc., Kyoto, Japan) supplemented with $10 \%$ fetal bovine serum (FBS) (Moregate, Brisbane, Australia) and penicillin-streptomycin solution $(\times 100)$ (Fujifilm Wako Pure Chemical Corporation, Osaka, Japan). Cells were maintained in a humidified environment with $5 \% \mathrm{CO}_{2}$ at $37^{\circ} \mathrm{C}$.

\section{Cell viability}

The effects of RK4 and resveratrol on the viability of $\mathrm{HeLa}$ cells were determined using methyl thiazolyl tetrazolium (MTT) assays. Briefly, logarithmically growing HeLa cells were seeded in 96-well plates at a density of $2 \times 10^{3}$ cells per well in $100 \mu \mathrm{L}$ of culture medium. After $24 \mathrm{~h}$ of pre-culture, cells were exposed to either RK4 (0, $3.13,6.25,12.5,25$, and $50 \mu \mathrm{M})$ or resveratrol $(0,12.5$, $25,50,100$, and $200 \mu \mathrm{M}$ ) for $24 \mathrm{~h}$. Next, $5.0 \mathrm{mg} / \mathrm{mL}$ MTT (Fujifilm Wako Pure Chemical Corporation) was added, and the cells were incubated at $37^{\circ} \mathrm{C}$ for an additional $3 \mathrm{~h}$. After discarding the medium, DMSO $(200 \mu \mathrm{L})$ was added, and the spectrophotometric absorbance at $535 \mathrm{~nm}$ was measured using a SPECTRA MAX 190 microplate reader (Molecular Devices, Osaka, Japan). The concentrations of RK4 and resveratrol, at which cell growth was inhibited by $50 \%\left(\mathrm{IC}_{50}\right)$, were calculated using the following formula:

$$
\text { Cell viability }(\%)=1-\left(\frac{\mathrm{A}_{\text {Sample }}-\mathrm{A}_{\text {Blank }}}{\mathrm{A}_{\text {Contlol }}-\mathrm{A}_{\text {Blank }}}\right) \times 100
$$

\section{Western blot analysis}

HeLa cells were seeded in $6 \mathrm{~cm}$ cell culture dishes at $6.0 \times 10^{5}$ cell/dish. After $24 \mathrm{~h}$ of pre-culture, cells were treated with RK4 (final concentrations 0, 0.2, 0.78, 3.13, 
and $12.5 \mu \mathrm{M}$ ) and resveratrol (final concentrations $0,0.2$, $0.78,3.13$, and $12.5 \mu \mathrm{M}$ ) for $48 \mathrm{~h}$. Then, the cells were dissolved in sodium dodecyl sulfate (SDS) sampling buffer (Nacalai Tesque, Inc.) containing 2-mercaptoethanol, protease inhibitor cocktail, phosphatase inhibitor cocktail I (Sigma-Aldrich), phosphatase inhibitor cocktail II (Sigma-Aldrich), $1 \mathrm{mM} \beta$-glycerophosphate, and $2.5 \mathrm{mM}$ sodium pyrophosphate, and boiled for $10 \mathrm{~min}$. Samples were electrophoresed on 5-20\% SDS-polyacrylamide gels (Atto Corporation, Tokyo, Japan) and then transferred to $0.1 \mu \mathrm{m}$ nitrocellulose (NC) membranes (Amersham Biosciences, Buckinghamshire, UK). Membranes were blocked with $20 \mathrm{mM}$ Tris- $\mathrm{HCl}$ (pH 7.6), $137 \mathrm{mM} \mathrm{NaCl}$, and $0.1 \%$ Tween-20 containing 5\% skim milk (Morinaga Co., Ltd., Tokyo, Japan) and treated with various (p38, PARP, and $\beta$-actin) antibodies. Immunoreactive protein bands were visualized using ECL Pro (PerkinElmer, Inc., MA, USA) detection reagent using a C-DiGiT blot scanner (LI-COR Corporate, NB, USA). The protein band intensities were quantified using software tools (Image Studio Digits 5.2.5) (LI-COR Corporate). Values were obtained from at least three independent experiments. All antibodies used in this experiment were obtained from Cell Signaling Technology (MA, USA).

\section{Statistical analysis}

All results are presented as means \pm SD of three independent experiments. Differences between control and RK4 or resveratrol treatments were performed using one-way analysis of variance (ANOVA). Control and treatment outcomes were compared using Student's unpaired $t$-test $(* P<0.05, * * P<0.01)$.

\section{Results}

\section{RK4 yields under various reaction conditions}

To investigate the reaction processes involved in RK4 formation, caffeic acid and resveratrol were reacted together under pressure conditions of 25, 50, 75, and 100 $\mathrm{MPa}$ at $90^{\circ} \mathrm{C}$ for $18 \mathrm{~h}$. Quantified results for RK4 abundance identified using LC-MS/MS are shown in Fig. 2. Concentrations of caffeic acid and resveratrol in reaction solutions $\mathrm{A}, \mathrm{B}$, and $\mathrm{C}$ were different, whereas the molar ratios were equivalent (caffeic acid:resveratrol $=2.53: 1$ ). The substrate content of each solution was as follows: solution A: caffeic acid $0.024 \mathrm{~g}$, resveratrol $0.012 \mathrm{~g}$; solution B: caffeic acid $0.12 \mathrm{~g}$, resveratrol $0.06 \mathrm{~g}$; solution C: caffeic acid $0.6 \mathrm{~g}$, resveratrol $0.3 \mathrm{~g}$. Values are expressed as means $\pm \mathrm{SD}(n=3)$. The production rate of $\mathrm{RK} 4$ at 25 $\mathrm{MPa}$ was $0.2 \pm 0.02 \%$ for reaction solution A, $0.7 \pm 0.02 \%$ for $\mathrm{B}$, and $1.2 \pm 0.04 \%$ for $\mathrm{C}$. At $50 \mathrm{MPa}$, the production rate of the reaction solution $\mathrm{A}$ was $0.3 \pm 0.02 \%$, B was $0.6 \pm 0.01 \%$, and $\mathrm{C}$ was $1.5 \pm 0.06 \%$. At $75 \mathrm{MPa}$, the rate

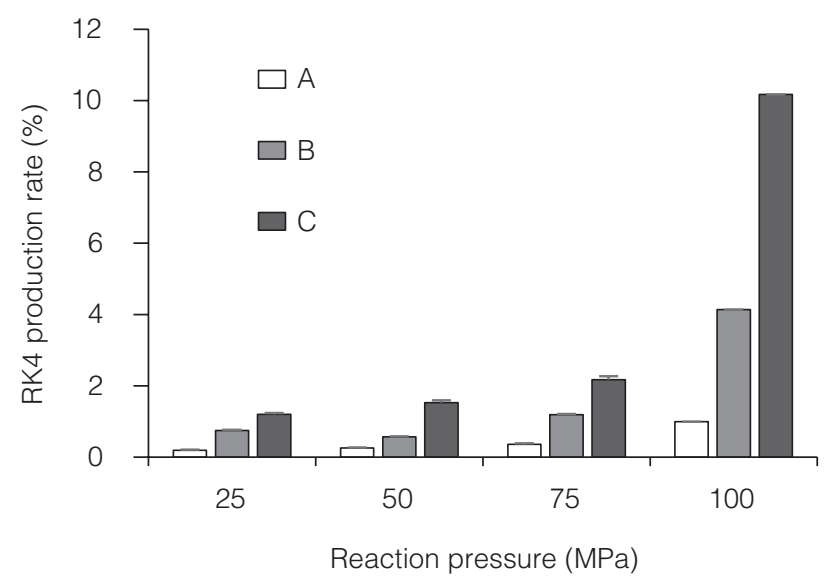

Fig. 2. RK4 production rates under various pressure conditions. The production rate of RK4 (the quantity of RK4 produced divided by the substrate content in the reaction solution) was quantified using LC-MS/MS. The reactants, including caffeic acid and resveratrol, were reacted at various pressures $(25,50,75$, and $100 \mathrm{MPa})$ for $18 \mathrm{~h}$ at $90^{\circ} \mathrm{C}$. Concentrations of the substrates (caffeic acid and resveratrol) in the solutions of $\mathrm{A}, \mathrm{B}$, and $\mathrm{C}$ were different, whereas the molar ratios were equivalent (caffeic acid:resveratrol $=2.53: 1$ ). The substrate content of each solution was as follows: solution A: caffeic acid $0.024 \mathrm{~g}$, resveratrol $0.012 \mathrm{~g}$; solution B: caffeic acid $0.12 \mathrm{~g}$, resveratrol $0.06 \mathrm{~g}$; solution $\mathrm{C}$ : caffeic acid $0.6 \mathrm{~g}$, resveratrol $0.3 \mathrm{~g}$. Values are expressed as means $\pm \operatorname{SD}(n=3)$.

of production of reaction solution A was $0.4 \pm 0.03 \%$, B was $1.2 \pm 0.02 \%$, and $\mathrm{C}$ was $2.2 \pm 0.1 \%$. At $100 \mathrm{MPa}$, the production rate of reaction solution $\mathrm{A}$ was $1.0 \%$, B was $4.1 \%$, and $\mathrm{C}$ was $10.2 \%$.

\section{Chemical kinetic analysis of RK4}

To investigate the relationship between the amount of RK4 produced and the reaction time under high-pressure conditions, reactions involving caffeic acid and resveratrol were carried out at $100 \mathrm{MPa}$ and $90^{\circ} \mathrm{C}$ for $1-18 \mathrm{~h}$. The substrate content of each solution was as follows. Solution A: caffeic acid $0.024 \mathrm{~g}$, resveratrol $0.012 \mathrm{~g}$; solution $\mathrm{B}$ : caffeic acid $0.12 \mathrm{~g}$, resveratrol $0.06 \mathrm{~g}$; solution $\mathrm{C}$ : caffeic acid $0.6 \mathrm{~g}$, resveratrol $0.3 \mathrm{~g}$. Values are expressed as means $\pm \mathrm{SD}(n=3)$. The results are shown in Fig. 3a. The production quantity at the reaction time of $1 \mathrm{~h}$ was $0.455 \pm$ $0.015 \mathrm{ppm}$ for reaction solution A, $1.23 \pm 0.016 \mathrm{ppm}$ for $\mathrm{B}$, and $1.23 \pm 0.031 \mathrm{ppm}$ for $\mathrm{C}$. The production amounts for reaction times of $3,5,6$, and $18 \mathrm{~h}$ were increased under all reaction conditions. In particular, at the reaction time of $18 \mathrm{~h}$, yields were remarkably increased in reaction solutions B and C. It was found that the amount of production was approximately $20 \mathrm{ppm}$ or less at $1-6 \mathrm{~h}$ and $18 \mathrm{~h}$ (reaction solution A), whereas the yield increased significantly to $60.2 \pm 0.479 \mathrm{ppm}$ in $\mathrm{B}$ and $108.6 \pm 1.56 \mathrm{ppm}$ in $\mathrm{C}$ at $18 \mathrm{~h}$. Furthermore, to perform a physicochemical analysis from the quantitative results of Fig. 3a, the relationship 
(a)

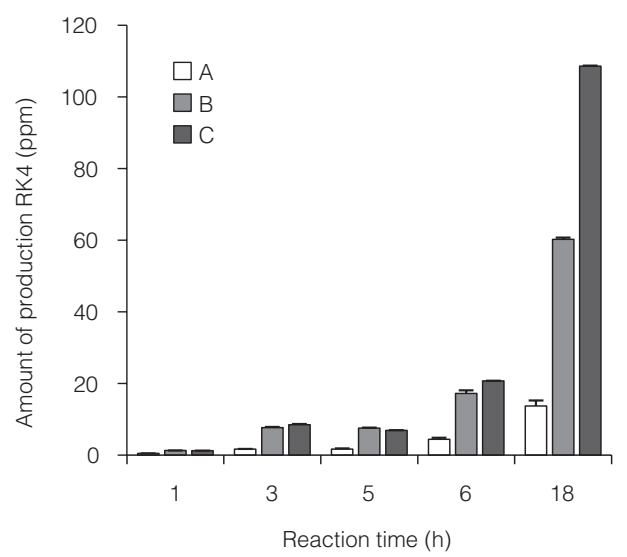

(b)

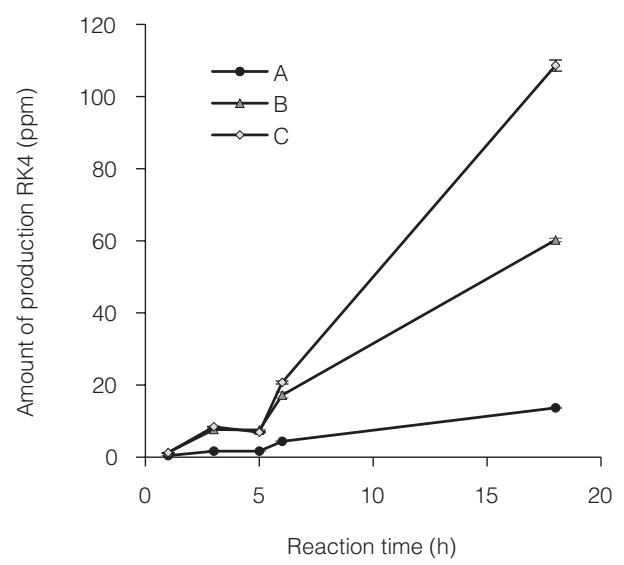

(c)

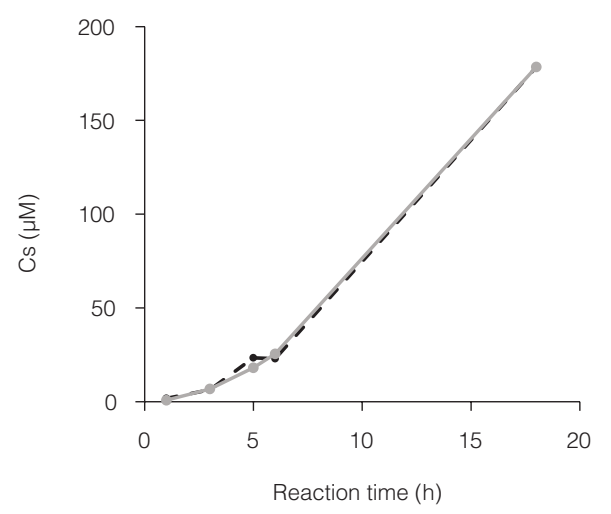

Fig. 3. Amounts of RK4 produced after various reaction times. (a) and (b) A solution of caffeic acid and resveratrol was reacted at $100 \mathrm{MPa}$ and $90{ }^{\circ} \mathrm{C}$ for $1-18 \mathrm{~h}$ to generate and subsequently quantify the amount of RK4. Quantitative results are shown as the amount produced (ppm). The substrate concentrations were different among A, B, and C. The substrate content of each solution was as follows. Solution A: caffeic acid $0.024 \mathrm{~g}$, resveratrol $0.012 \mathrm{~g}$; solution B: caffeic acid $0.12 \mathrm{~g}$, resveratrol $0.06 \mathrm{~g}$; solution $\mathrm{C}$ : caffeic acid $0.6 \mathrm{~g}$, resveratrol $0.3 \mathrm{~g}$. Values are expressed as means $\pm \mathrm{SD}(n=3)$. (c) A graph edited to identify rate coefficients. The dotted line represents measured values, and the solid line is the simulated graph from which the rate coefficients were calculated. between the production amount and the reaction time was represented as a line graph, as shown in Fig. 3b. From the results shown in Fig. $3 \mathrm{~b}$, the sequential reactive relationship between the production amount of RK4 and the reaction time was observed. Furthermore, the rate coefficient in the production reaction of RK4 was determined using Equation 1, which expresses the relationship between substrate and product concentrations in the sequential reaction. Specifically, by substituting the expected values of $k_{1}$ and $k_{2}$ into Equation 1, the shape was used as a line graph depicting the relationship between reaction time and the production of RK4 (Cs) (Fig. 3c). The reaction rate constant $\left(k_{1}\right)$ involving caffeic acid and resveratrol at intermediate formation stages was approximately $k_{1}$ $=0.02$, and the rate coefficient $\left(k_{2}\right)$ from the intermediate to the formation of RK4 was approximately $k_{2}=0.046$.

\section{RK4 inhibits HeLa cell viability}

The antiproliferative effects of RK4 and resveratrol on cancer cell viability were measured using the MTT method to compare the effects of the two food factors in vitro. HeLa cells were exposed to various concentrations of reagents (RK4 or resveratrol) for $24 \mathrm{~h}$. Both RK4 and resveratrol exerted significant growth inhibitory effects on HeLa cells in a concentration-dependent manner (Fig. 4). Cell survival rates after RK4 treatment were 97.9 $\pm 8.08,66 \pm 5.53,58.5 \pm 4.6,46.9 \pm 5.84$, and $8.2 \pm 3.44 \%$ at $3.13,6.25,12.5,25$, and $50 \mu \mathrm{M}$, respectively, and the $\mathrm{IC}_{50}$ value was $23.6 \mu \mathrm{M}$. Cell survival rates after resveratrol treatment were $106.2 \pm 6.26,108.1 \pm 10.8,111.1 \pm$ $2.19,77.8 \pm 2.07$, and $16.9 \pm 11.5 \%$ at $2.5,25,50,100$, and $200 \mu \mathrm{M}$, respectively, and the $\mathrm{IC}_{50}$ was $145.3 \mu \mathrm{M}$.

\section{RK4 induces apoptosis in HeLa cells}

To investigate the mechanism by which RK4 causes cytotoxicity to HeLa cells, the cells were treated with various concentrations of RK4 and resveratrol for $48 \mathrm{~h}$ (Fig. 5). Activation of p38 was observed in cells treated with RK4, whereas no activation was observed in cells treated with resveratrol (Fig. 5a and b). In addition, in cells treated with RK4, a gradual decrease in ADP-ribose polymerase (PARP) was observed in a concentration-dependent manner, and a marked increase in its cleaved form was also noted. In cells treated with resveratrol, PARP levels tended to decrease, while its cleavage form could not be detected (Fig. 5a, c, and d).

\section{Discussion}

\section{Relationship between RK4 production and high-pressure} processing

We previously reported that temperature and pressure are important factors in RK4 formation (19). However, the 

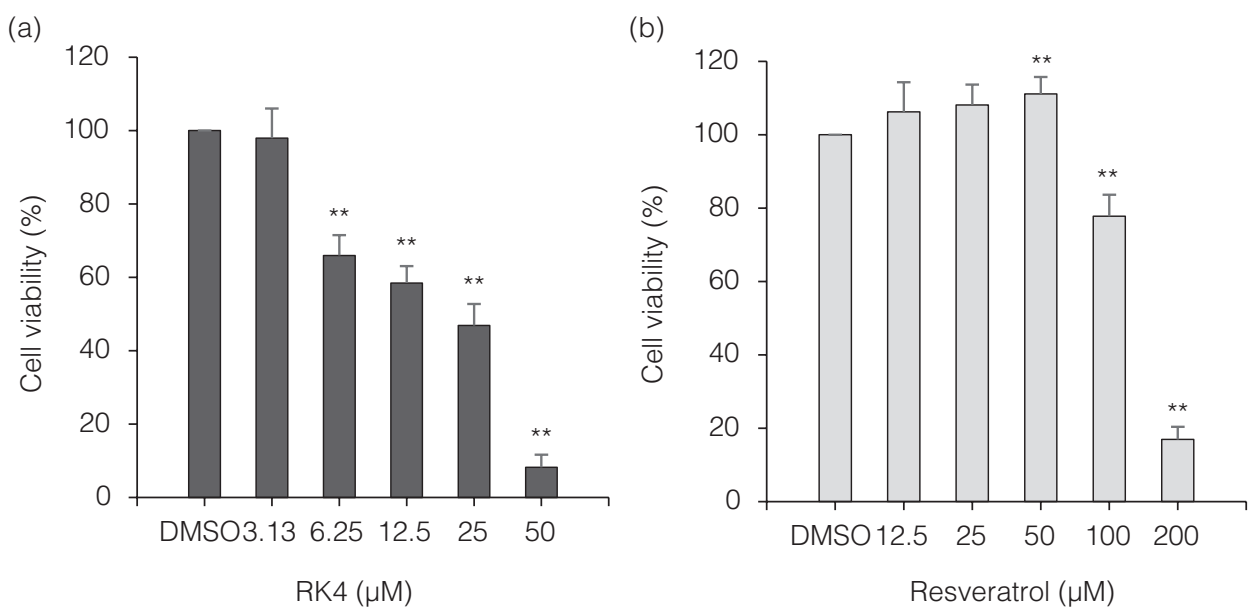

Fig. 4. Growth inhibitory effects of RK4 and resveratrol on HeLa cells. (a) HeLa cells were treated with RK4 (0, 3.13, 6.25, $12.5,25$, and $50 \mu \mathrm{M})$ for $24 \mathrm{~h}$. (b) HeLa cells were treated with resveratrol $(0,12.5,25,50,100$, and $200 \mu \mathrm{M})$ for $24 \mathrm{~h}$. Values are expressed as means $\pm \mathrm{SD}(n=3)$. Statistical significance: $* P<0.05, * * P<0.001$, compared with control (DMSO).

contribution of pressure in the formation of RK4 and its relationship with other conditions such as temperature and reaction time have not been clearly identified.

In particular, high-pressure treatment of foods is one of the attractive treatments available in food processing methods because of its convenience. Therefore, in this study, to understand the relationship between the formation of a novel resveratrol derivative (RK4) and high-pressure treatment, resveratrol and caffeic acid were reacted under various conditions, and then quantitative analysis of RK4 by LC-MS/MS was performed. The experiments were conducted by changing the pressure, temperature, and time. It was found that pressure treatment significantly contributed to the formation of RK4, and that reaction time and concentration of the reactant solution were also important, as shown in Figs. 2 and 3.

As presented in Fig. 2, the RK4 production rate under pressure conditions of $75 \mathrm{MPa}$ or lower was small, and difference in the production rate between the reaction solutions $\mathrm{A}, \mathrm{B}$, and $\mathrm{C}$ was $<2 \%$. However, a high production rate was confirmed in reaction solutions $\mathrm{B}$ and $\mathrm{C}$ at $100 \mathrm{MPa}$. Compared to the production rate under the condition of $75 \mathrm{MPa}$ or less, the rate of reaction solution $\mathrm{B}$ was approximately twice as fast, and the rate of solution $\mathrm{C}$ was four or more times faster. In particular, reaction solution $\mathrm{C}$ at $100 \mathrm{MPa}$ exhibited a remarkably high reaction rate of $10.2 \%$, suggesting a strong relationship between production efficiency and reaction conditions such as pressure and substrate concentration. This result suggested that a high-pressure condition of $100 \mathrm{MPa}$ is effective for the production of RK4.

Furthermore, in order to investigate potentially more efficient reaction conditions, we focused on the relationship between the amount of RK4 produced and reaction times. The yield of RK4 tended to increase when the reaction time was prolonged (Fig. 3a). Moreover, from the results of Fig. 3b, it was suggested that the RK4 formation reaction is sequential in that it proceeds via an intermediate. Next, we analyzed possible mechanisms involved using Equation 1, which expresses the relationship between substrate concentration (resveratrol) and product concentration (RK4). Using Equation 1, the RK4 production reaction was assumed to be sequential. Additionally, it was found that there was an approximate twofold difference between the reaction rate coefficient $\left(k_{1}\right)$ for resveratrol in intermediate formation and the reaction rate coefficient $\left(k_{2}\right)$ from the intermediate to the formation of RK4 $\left(2 k_{1} \risingdotseq k_{2}\right)$. This result indicated that there is an approximate two-fold difference in the progress rate of the reaction in the two-step reaction sandwiching the intermediate until RK4 formation. For more efficient production of RK4, it is important to increase the reaction rate at the reaction time of approximately $1-5 \mathrm{~h}$, as shown in Fig. 3b, which is assumed to be the first stage of the reaction.

\section{Effects of RK4 on cancer cells}

$\mathrm{RK} 4$, which is the main subject of this study, is a newly discovered derivative of resveratrol. Thus far, it has been suggested that RK4 has stronger effects than resveratrol on various bioactivities. Cancer cell growth inhibitory activity is one such activity, and RK4 has been suggested as a potential alternative to resveratrol in cancer research (19). In this study, we investigated the growth inhibitory activity of RK4 and its mechanism of action in HeLa cells. We confirmed that RK4 has a greater antiproliferative inhibitory effect than resveratrol and identified a number of the target molecules involved in induction of apoptosis by RK4.

Currently, food factors that can selectively induce apoptosis in cancer cells have received much attention 
(a)

\begin{tabular}{lllll}
\multicolumn{8}{c}{$\operatorname{RK} 4(\mu \mathrm{M})$} \\
\hline 0 & 0.2 & 0.78 & 3.13 & 12.5
\end{tabular}

\begin{tabular}{lllll}
\multicolumn{6}{c}{ Resveratrol $(\mu \mathrm{M})$} \\
\hline 0 & 0.2 & 0.78 & 3.13 & 12.5
\end{tabular}
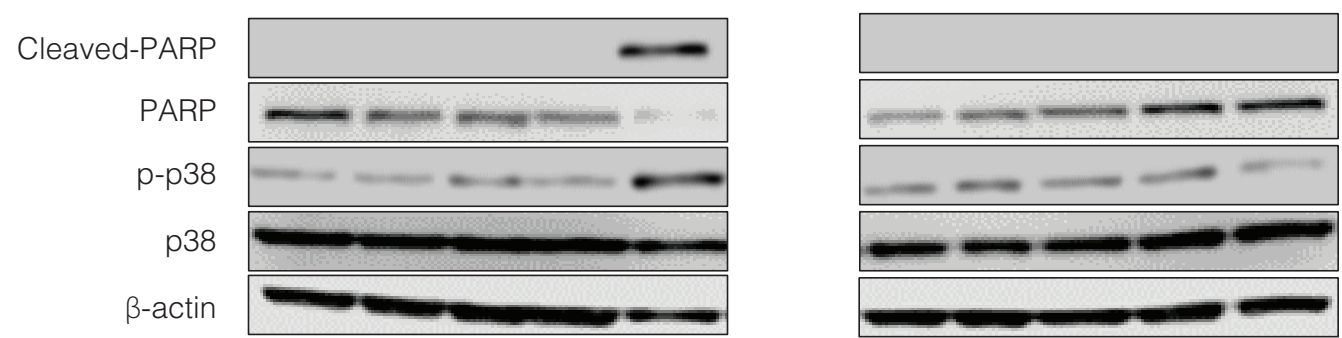

(b)
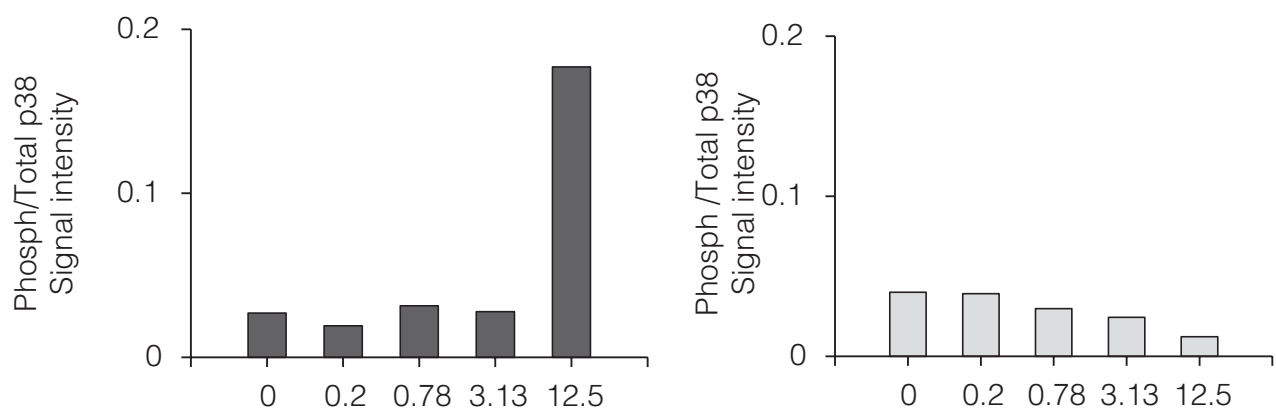

(c)

$\mathrm{RK} 4(\mu \mathrm{M})$
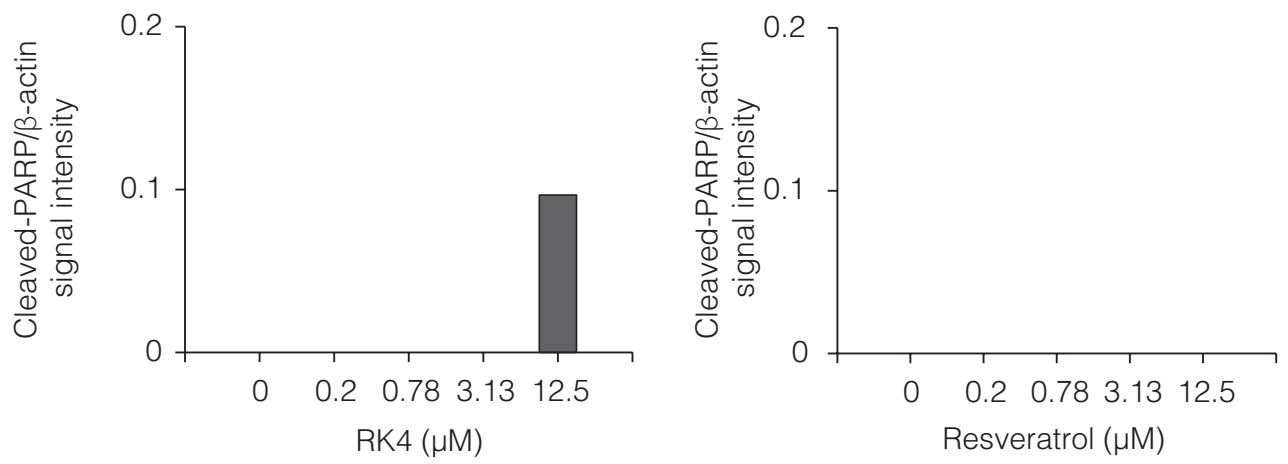

(d)
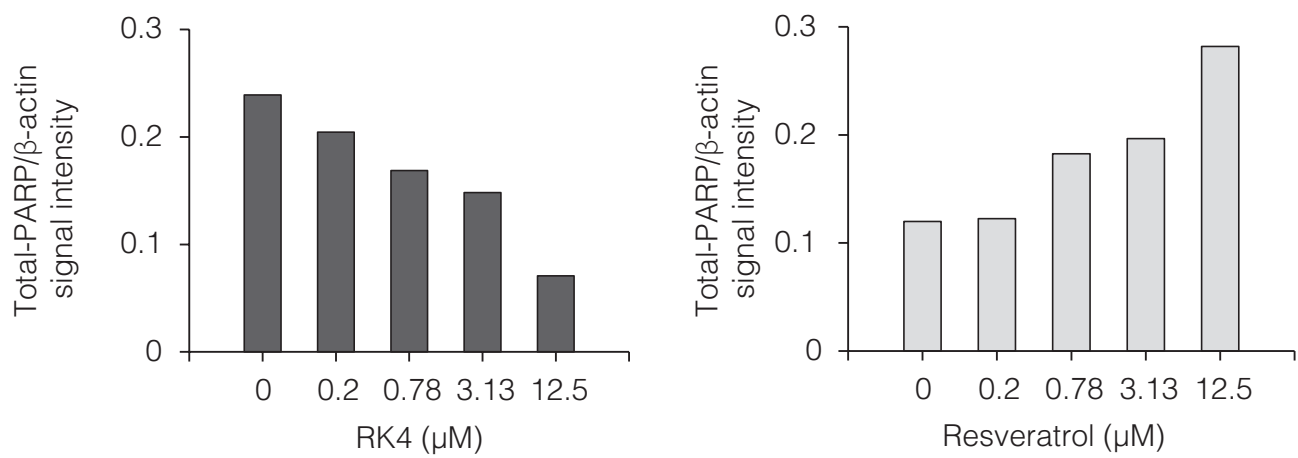

Fig. 5. RK4 activated p 38 and cleaved PARP at lower concentrations than resveratrol. Cellular proteins were isolated from HeLa cells treated with various concentrations of RK4 or resveratrol $(0,0.2,0.78,3.13$, and $12.5 \mu \mathrm{M})$ for 48 h. (a) Changes in p38 and PARP abundance were analyzed by western blotting. Each experiment was repeated at least three times, and representative data are shown. (b-d) Protein-level densitometric analysis of apoptosis-related proteins isolated from Hela cells treated with RK4 and resveratrol. The values shown represent the detection intensities of each target protein divided by the detection intensity of the precursor or $\beta$-actin. This experiment was performed at $n=3$, and only representative values are displayed. 
in the development of new approaches to cancer prevention. Many natural substances already employed in cancer chemotherapy also have apoptosis-inducing activity, and the anticancer properties of these substances are thought to be partly due to induction of apoptosis (30-32). Resveratrol, which is a precursor of RK4 and was used as a molecule for comparison in this study, is a compound that has high bioactivities and is highly anticipated as a functional phytochemical (2, 3, 10-17). Caffeic acid is a natural phenolic acid product found in fruits (33), wine $(34,35)$, and coffee (36). It has been reported to exert diverse biological activities such as antibacterial (36), antioxidative (37), and anti-inflammatory (34) effects, which are similar to induction by resveratrol. These two compounds, which are precursors of RK4, have been reported to induce apoptosis in various cancer cells, and some of the mechanisms involved have been elucidated $(24,25,38,39)$.

The $\mathrm{IC}_{50}$ values were $23.6 \mu \mathrm{M}$ for RK4 and $145.3 \mu \mathrm{M}$ for resveratrol. These values indicated that RK4 exerts greater growth inhibitory effects on HeLa cells than resveratrol, and our results strongly suggested its potential as a functional food component. Western blotting analysis revealed that RK4 strongly induced p38 activation. In addition, there was no activation of p38 by resveratrol. These results suggested that RK4 may induce stressresponsive apoptosis in HeLa cells. In addition, it was shown that RK4 induced the cleavage of PARP, and this result supported the effect of RK4 in inducing apoptosis in HeLa cells. A schematic diagram of a proposed

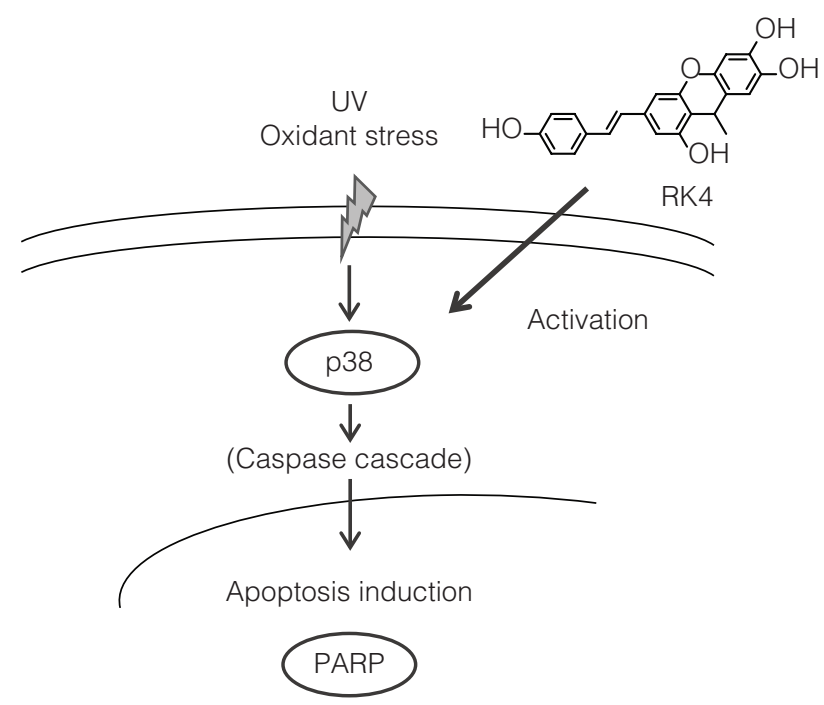

Fig. 6. Schematic diagram of apoptosis induction by RK4. Extracellular environments involving UV and oxidative stress are known to promote the production of intracellular reactive oxygen species and induced stress-responsive apoptosis. RK4 may increase such extracellular or internal stress, activate the p38 MAPK cascade, and induce apoptosis. pathway by which RK4 acts on cancer cells is presented in Fig. 6. This study showed that RK4 is a more potent inducer of apoptosis than that of resveratrol, and further supports the idea that it represents a promising candidate for an antitumor agent. However, since only a small number of protein markers of apoptotic induction were successfully detected in this study compared with previous reports, it will be necessary to investigate other such apoptotic markers in order to further elucidate the mechanisms of action of RK4.

\section{Conclusions}

In this study, the quantification of RK4 in high-pressuretreated sample indicated that the component composition of foodstuffs is significantly modified by high-pressure treatment, and that such alterations may yield components other than RK4 with similar high bioactivities. High-pressure processing has been reported to be an innovative non-thermal food preservation method because it can inactivate microorganisms with minimal influence on the physicochemical and sensory properties of foods (40-42). However, there are few studies on the increase of the functional component(s) by high-pressure processing as far as we know. Thus, we have demonstrated the potential importance of high-pressure processing in future food production and the value of RK4 as a functional food ingredient.

\section{Acknowledgements}

We thank Professor Makoto Shimoyamada (University of Shizuoka, Japan) and Doctor Hayato Masuda (Osaka City University, Japan) for their valuable suggestions to this study.

\section{Conflicts of interests}

The authors declare no potential conflicts of interest.

\section{References}

1. Yamada T, Hayasaka S, Shibata Y, Ojima T, Saegusa T, Gotoh $\mathrm{T}$, et al. Frequency of citrus fruit intake is associated with the incidence of cardiovascular disease: the Jichi Medical School cohort study. J Epidemiol 2011; 21: 169-75. doi: 10.2188/jea. JE20100084

2. Mursu J, Virtanen JK, Tuomainen TP, Nurmi T, Voutilainen S. Intake of fruit, berries, and vegetables and risk of type 2 diabetes in Finnish men: the kuopio ischaemic heart disease risk factor study. Am J Clin Nutr 2014; 9: 328-33. doi: 10.3945/ ajen.113.069641

3. Kruk J. Association between vegetable, fruit and carbohydrate intake and breast cancer risk in relation to physical activity. Asian Pac J Cancer Prev 2014; 15: 4429-36. doi: 10.7314/ APJCP.2014.15.11.4429

4. Kyro C, Skeie G, Loft S, Landberg R, Christensen J, Lund E, et al. Intake of whole grains from different cereal and food sources and incidence of colorectal cancer in the Scandinavian HELGA 
cohort. Cancer Causes Control 2013; 24: 1363-74. doi: 10.1007/ s10552-013-0215-Z

5. Wang LF, Chen JY, Xie HH, Ju XR, Liu RH. Phytochemical profiles and antioxidant activity of adlay varieties. J Agric Food Chem 2013; 61: 5103-13. doi: 10.1021/jf400556s

6. Prahalathan P, Saravanakumar M, Raja B. The flavonoid morin restores blood pressure and lipid metabolism in DOCA-salt hypertensive rats. Redox Rep 2012; 17: 167-75. doi: 10.1179/1351000212Y.0000000015

7. St Leger AS, Cochrane A, Moore F. Factors associated with cardiac mortality in developed countries with particular reference to the consumption of wine. Lancet 1979; 313: 1017-20. doi: 10.1016/S0140-6736(79)92765-X

8. Renaud S, De Lorgeril M. Wine, alcohol, platelets, and the French paradox for coronary heart disease. Lancet 1992; 339: 1523-6. doi: 10.1016/0140-6736(92)91277-F

9. Frankel EN, Waterhouse AL, Kinsella JE. Inhibition of human LDL oxidation by resveratrol. Lancet 1993; 341: 1103-4. doi: 10.1016/0140-6736(93)92472-6

10. Shukla Y, Singh R. Resveratrol and cellular mechanisms of cancer prevention. Ann NY Acad Sci 2011; 1215: 1-8. doi: 10.1111/j.1749-6632.2010.05870.x

11. Malaguarnera L. Influence of resveratrol on the immune response. Nutrients 2019; 11: 946. doi: 10.3390/nu11050946

12. Li H, Xia N, Hasselwander S, Daiber A. Resveratrol and vascular function. Int J Mol Sci 2019; 20: 2155. doi: 10.3390/ ijms20092155

13. Park SJ, Ahmad F, Philp A, Baar K, Williams T, Luo H, et al. Resveratrol ameliorates aging-related metabolic phenotypes by inhibiting camp phosphodiesterases. Cell 2012; 148: 421-33. doi: 10.1016/j.cell.2012.01.017

14. Howitz KT, Bitterman KJ, Cohen HY, Lamming DW, Lavu S, Wood JG, et al. Small molecule activators of sirtuins extend Saccharomyces cerevisiae lifespan. Nature 2014; 19: 191-6. doi: 10.1038/nature01960

15. Baur JA, Pearson KJ, Price NL, Jamieson HA, Lerin C, Kalra A, et al. Resveratrol improves health and survival of mice on a high-calorie diet. Nature 2006; 444: 337-42. doi: 10.1038/ nature 05354

16. Timmers S, Konings E, Bilet L, Houtkooper RH, Van De Weijer T, Goossens GH, et al. Calorie restriction-like effects of 30 days of resveratrol supplementation on energy metabolism and metabolic profile in obese humans. Cell Metab 2011; 14: 612-22. doi: 10.1016/j.cmet.2011.10.002

17. Lagouge M, Argmann C, Gerhart-Hines Z, Meziane H, Lerin C, Daussin F, et al. Resveratrol improves mitochondrial function and protects against metabolic disease by activating sirt 1 and Pgc-1 $\alpha$. Cell 2006; 127: 1109-22. doi: 10.1016/j.cell.2006. 11.013

18. Kishi A, Shinka Y, Matsukawa T, Yamada Y, Yamada I. A novel resveratrol derivative. Japan Patent 2016; 30739.

19. Okamoto H, Matsukawa T, Doi S, Tsunoda T, Sawata Y, Naemura $\mathrm{M}$, et al. A novel resveratrol derivative selectively inhibits the proliferation of colorectal cancer cells with KRAS mutation. Mol Cell Biochem 2018; 442: 39-45. doi: 10.1007/ s11010-017-3191-x

20. Shimada A, Kasai M, Yamamoto A, Hatae K. Changes in the palatability of foods by hydrostatic pressurizing. Nippon Shokuhin Kogyo Gakkaishi (in Japanese) 1990; 37: 511-19. doi: 10.3136/nskkk1962.37.7_511

21. Signorelli P, Ghidoni R. Resveratrol as an anticancer nutrient: molecular basis, open questions and promises. J Nutr Biochem 2005; 16: 449-66. doi: 10.1016/j.jnutbio.2005.01.017
22. Carrizzo A, Forte M, Damato A, Trimarco V, Salzano F, Bartolo $\mathrm{M}$, et al. Antioxidant effects of resveratrol in cardiovascular, cerebral and metabolic diseases. Food Chem Toxicol 2013; 61: 215-26. doi: 10.1016/j.fct.2013.07.021

23. Jang M, Cai L, Udeani GO, Slowing KV, Thomas CF, Beecher $\mathrm{CW}$, et al. Cancer chemopreventive activity of resveratrol, a natural product derived from grapes. Science 1997; 275: 218-20. doi: $10.1126 /$ science.275.5297.218

24. Fouad MA, Agha AM, Merzabani MM, Shouman SA. Resveratrol inhibits proliferation, angiogenesis and induces apoptosis in colon cancer cells: calorie restriction is the force to the cytotoxicity. Hum Exp Toxicol 2013; 32: 1067-80. doi: 10.1177/0960327113475679

25. Carter LG, D'Orazio JA, Pearson KJ. Resveratrol and cancer: focus on in vivo evidence. Endocr Relat Cancer 2014; 21: R209-25. doi: 10.1530/ERC-13-0171

26. Li L, Qiu RL, Lin Y, Cai Y, Bian Y, Fan Y, et al. Resveratrol suppresses human cervical carcinoma cell proliferation and elevates apoptosis via the mitochondrial and p53 signaling pathways. Oncol Lett 2018; 15: 9845-51. doi: 10.3892/ol. 2018.8571

27. Zhang L, Yang X, Li X, Li C, Zhao L, Zhou Y, et al. Butein sensitizes HeLa cells to cisplatin through the AKT and ERK/p38 MAPK pathways by targeting FoxO3a. Int J Mol Med 2015; 36: 957-66. doi: 10.3892/ijmm.2015.2324

28. Liu Z, Wu X, Lv J, Sun H, Zhou F. Resveratrol induces p53 in colorectal cancer through SET7/9. Oncol Lett 2019; 17: 3783-9. doi: 10.3892/ol.2019.10034

29. Cohen GM. Caspases: the executioners of apoptosis. Biochem J 1997; 326: 1-16. doi: 10.1042/bj3260001

30. Gorczyca W, Gong J, Ardelt B, Traganos F, Darzynklewiez Z. The cell cycle-related differences in susceptibility of HL-60 cells to apoptosis induced by various antitumor agents. Cancer Res 1993; 53: 3186-92.

31. Xiao D, Zhu SP, Gu ZL. Quercetin induced apoptosis in human leukemia HL-60 cell. Acta Pharmacol Sinica 1998; 18: 280-3.

32. Yin F, Giuliano AE, Van Herle AJ. Signal pathways involved in apigenin inhibition of growth and induction of apoptosis of human anaplastic thyroid cancer cells (ARO). Anticancer Res 1999; 19: 4297-303.

33. Hsu FL, Chen YC, Cheng JT. Caffeic acid as active principle from the fruit of Xanthium strumarium to lower plasma glucose in diabetic rats. Planta Med 2000; 66: 228-30. doi: 10.1055/ s-2000-8561

34. Giovannini L, Migliori M, Filippi C, Origlia N, Panichi V, Falchi $\mathrm{M}$, et al. Inhibitory activity of the white wine compounds, tyrosol and caffeic acid, on lipopolysaccharide-induced tumor necrosis factor-alpha release in human peripheral blood mononuclear cells. Int J Tissue React 2002; 24: 53-6.

35. Simonetti P, Gardana C, Pietta P. Caffeic acid as biomarker of red wine intake. Methods Enzymol 2001; 335: 122-30. doi: 10.1016/S0076-6879(01)35237-0

36. Almeida AA, Farah A, Silva DA, Nunan EA, Gloria MB. Antibacterial activity of coffee extracts and selected coffee chemical compounds against enterobacteria. J Agric Food Chem 2006; 54: 8738-43. doi: 10.1021/jf0617317

37. Chung MJ, Walker PA, Hogstrand C. Dietary phenolic antioxidants, caffeic acid and Trolox, protect rainbow trout gill cells from nitric oxide-induced apoptosis. Aquat Toxicol 2006; 80: 321-8. doi: 10.1016/j.aquatox.2006.09.009

38. Rao K, Indap M, Radhika S, Motiwale L. Anticancer activity of phenolic antioxidants against breast cancer cells and a 
spontaneous mammary tumor. Indian J Pharm Sci 2006; 68: 470-6. doi: 10.4103/0250-474X.27820

39. Rezaei-Seresht H, Cheshomi H, Falanji F, Movahedi-Motlagh F, Hashemian M, Mireskandari E. Cytotoxic activity of caffeic acid and gallic acid against MCF-7 human breast cancer cells: an in silico and in vitro study. Avicenna J Phytomed 2019; 9: 574-86. doi: 10.22038/AJP.2019.13475

40. Abera G. Review on high-pressure processing of foods. Cogent Food Agric 2019; 5: 1568725. doi: 10.1080/23311932. 2019.1568725

41. Balakrishna AK, Wazed MA, Farid M. A review on the effect of high pressure processing (HPP) on gelatinization and infusion of nutrients. Molecules 2020; 25: 2369. doi: 10.3390/ molecules 25102369

42. Govaris A, Pexara A. Inactivation of foodborne viruses by high-pressure processing (HPP). Foods 2021; 10: 215. doi: 10.3390/foods 10020215

\section{*Toshiro Ohta}

Graduate School of Integrated Pharmaceutical and Nutrition Sciences

University of Shizuoka, 52-I Yada, Suruga-ku

Shizuoka 422-8526, Japan

Tel.: +8I 54264 557।; Fax: +8I 54264 557l.

Email: ohtat@u-shizuoka-ken.ac.jp

\section{*Shigenori Kumazawa}

Graduate School of Integrated Pharmaceutical and Nutrition Sciences

University of Shizuoka, 52- I Yada, Suruga-ku

Shizuoka 422-8526, Japan

Tel.: +8I 54264 5523; Fax: +8I 542645523.

Email:kumazawa@u-shizuoka-ken.ac.jp 